\title{
Analysis of Relation and Variation Characteristics Between Soil Water and Groundwater in Planting Conditions
}

\author{
Wanxin Li, Junqi He \\ School of Environmental Science and Engineering, Changan University, Xi`an, China
}

\section{Email address:}

121589998@qq.com (Wanxin Li)

\section{To cite this article:}

Wanxin Li, Junqi He. Analysis of Relation and Variation Characteristics Between Soil Water and Groundwater in Planting Conditions. Earth Sciences. Vol. 4, No. 6, 2015, pp. 235-240. doi: 10.11648/j.earth.20150406.13

\begin{abstract}
The station located in Aksu region is distributed under the Tarim Basin oasis which is in arid condition, it is the largest cotton producing area in China, also is has the greatest changes in the Tarim Basin. The study of arid farmland ecosystem water oasis, salinity and nutrient rule change process, water-saving irrigation technology demonstration theory and the ideal place for the sustainable development of agriculture and the oasis are very typical representative. In this paper, we make cotton growing soil water - groundwater changes as the study objection, focusing on the analysis of soil moisture in farmland ecosystem and the correlation between groundwater. The basic data of this paper came from experimental field station in Aksu, such as--soil moisture, groundwater depth, they are segmented by cotton fertility cycle in order to analyze soil moisture trends, combined with the local irrigation analysis of soil moisture under different irrigation curves, finally, we will combine these conclusions with evaporation, temperature and other weather station related data, then make a comprehensive analysis of the relationship between soil water, groundwater depth and amount of irrigation, evaporation. We draw the following conclusions: First, the characteristics of soil moisture conditions analysis can divide the soil into four layers: dramatic changes in the surface layer $(0 \sim 30 \mathrm{~cm})$, water supply layer $(30 \sim 50 \mathrm{~cm})$, graded layer $(50 \sim 100 \mathrm{~cm})$ and are stable layer(100 150cm); Secondly, we found that under different irrigation amount, different evaporation affected by different growth stages of cotton water requirements of different factors; Finally, we fit the trend line chart with two lines means a comprehensive analysis of the soil water - groundwater relationship, while the thesis raised the topic in favor of crop irrigation proposal.
\end{abstract}

Keywords: Soil Moisture, Meteorological Condition, Plant Reproductive Cycle, Evaporation, Groundwater Depth

\section{Introduction}

For a long time, study on the variation characteristics of soil water and groundwater only on fundamental principle of mass conservation, this artificial segmentation of continuous dynamic changes are lack of combining with the environmental conditions. Since Philip proposed SPAC (soil-plant-atmosphere continuum) theory, research on soil moisture and balance in farmland soil-plant water relations and groundwater-soil-water into the atmosphere are based on SPAC continuum, for the analysis of moisture migration and energy into dynamic process provides a new theory. Cheng and Wang [1] investigated the relation between vegetation and groundwater in the hinterland of $\mathrm{Mu}$ Us Desert with 6 indicators, such as vegetation populations and cover, groundwater depth and mineralization etc. Han and Jing [2] analyze the transformation mechanism between soil water and groundwater in planting conditions by controlling the depth of groundwater, introduce the concept---critical depth of water balance $\mathrm{Z}_{0}$. He and Ren [3] investigated the spatial variation of soil moisture characteristics, from different soil moisture changes in plot, study were analyzed under different irrigation.

In 1970s, scholar proposed the concept of Soil Water Resource, after years of research, Soil Water Resource are widely recognized as an important natural resource. However soil water was influenced by landforms, vegetation factors, they lose continuity in spatial; Influenced by climate, rainfall, they lose continuity in temporal. That's to say, on the studying of variation characteristics of soil water-groundwater, and their dynamics research, will help improving soil water resources property of awareness, solve the problem of effectiveutilization of soilwater, related conclusion's applicants in farming operation management can also exert their benefits. 


\section{The Study Area Overview}

\subsection{Study Site}

Aksu Oasis Field Ecosystem Field Scientific Observation Station is located in Xinjiang Aksu, geographical coordinates $80^{\circ} 45^{\prime} 37^{\prime \prime} \mathrm{E} 40^{\circ} \mathrm{N}, 1028 \mathrm{~m}$ above the sea level. Aksu area in Tarim Basin, they are under extreme drought conditions. It is one of the biggest cotton-producing areas, groundwater has the most dramatic changes in Tarim Basin, so it is an ideal place to do research of agricultural development in oasis.

\subsection{Plant Growth Condition in Study Site}

Cotton in this study site are early-maturing variety and super early-maturing variety, growth period is divided into 5 stages, they are seedings,seeding stage, bud stage, boll-forming stage and boll-opening stage. As root crops, they are sensitive to moisture, $65 \% \sim 80 \%$ is beneficial to seeding; Drought affects seedling emergence; Rain makes cotton field compaction; Rainy makes poor root development, and susceptible to seedling diseases. Study on growing relation between soil water and groundwater under planting condition will help putting forward reasonable proposals for irrigation.

\section{Theory and Experiment}

\subsection{Theory}

Transfer of soil water under growing conditions to groundwater is mainly reflected in the precipitation and irrigation, from groundwater to soil water is in forms of evaporation and plant transpiration. The create and rate of infiltrationrecharge and evaporation are mainly controlled by the energy and quantity distribution of soil water and hydraulic conductivity and other factors. In areas above the water table, if soil water potential gradient is less than zero, moisture migration will take place, causing evaporation.
When the gradient is greater than zero, the downward movement of soil water will happened unconfinedwater be under soil moisture recharge.

\subsection{Experimental Methods}

The experimental observation took place in Aksu Oasis Field Ecosystem Field Scientific Observation Station. The research area is in the shape of rectangle, $50 \mathrm{~m}$ long and $90 \mathrm{~m}$ wide, with cotton were grown in this area.

Comprehensive observations of neutrontube (AKAZH01CTS-01) was in the experimental site. Monthly, 5 th, 10th, 15th, 20th, 25th, 30th, or 31st were the observation day, also measured before and after the irrigation. Observing depth of soil below the surface, they are $10 \mathrm{~cm}, 20 \mathrm{~cm}, 30 \mathrm{~cm}$, $40 \mathrm{~cm}, 50 \mathrm{~cm}, 70 \mathrm{~cm}, 90 \mathrm{~cm}, 110 \mathrm{~cm}, 130 \mathrm{~cm}, 150 \mathrm{~cm}---$ ten layers.

Comprehensive observations of groundwater depth (AKAZH01CDX-01) took place in the spot I and spot II, observation frequence was the same as before.

The evaporation rate were calculated by water balance principle, the equation is: $\mathrm{ET}=\mathrm{W}_{1}-\mathrm{W}_{2}+\mathrm{R}, \mathrm{ET}$ is the evaporation rate, $\mathrm{W}_{1}$ is the soil moisture storage at the beginning, $\mathrm{W}_{2}$ is the soil moisture storage in the end. This method is wildly used in arid areas.

\section{Analysis and Data Processing}

This article selected the data from November 10, 2006 to November 11, 2007. This period was a whole year; also it is the growth cycle of cotton.

\subsection{Characteristics of Soil Moisture Curve Under Different Irrigation Volume}

Cotton in Aksu station were irrigated by canal, we will analyze the Characteristics of soil moisture curve before and after the irrigation.

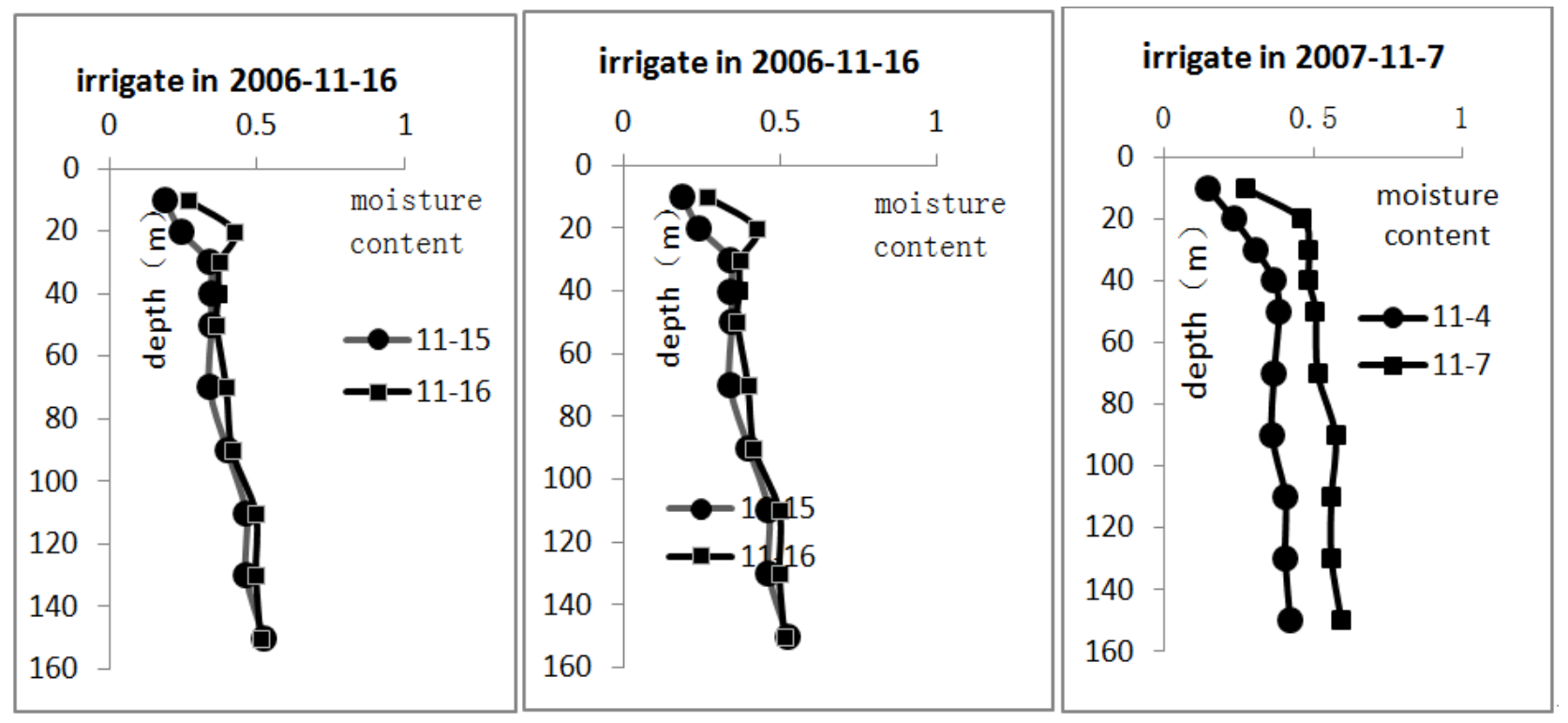

Figure 1. Changes of soil moisture curve when the irrigationvolume is $3000 \mathrm{~m}^{3} / \mathrm{hm}^{2}$. 


\section{irrigate in 2007-7-10}

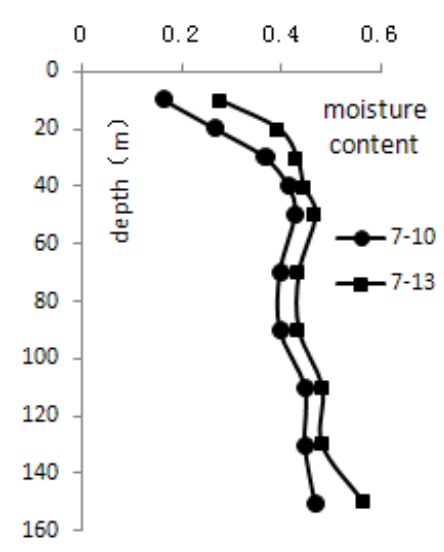

irrigate in 2007-7-23

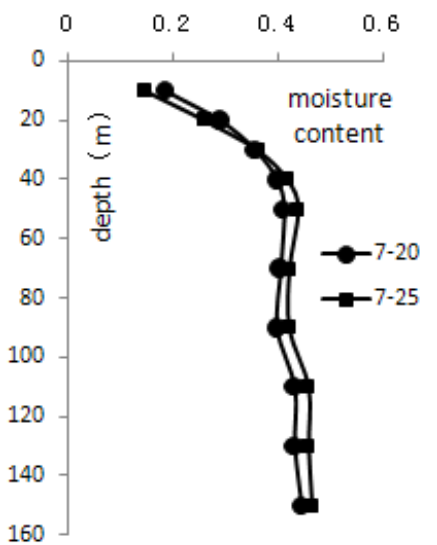

irrigate in 2007-8-16

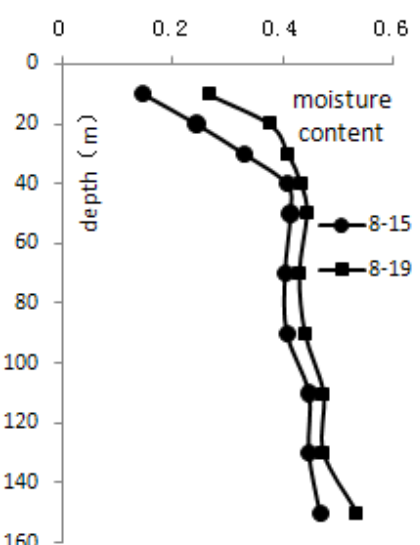

Figure 2. Changes of soil moisture curve when the irrigationvolume is $2250 \mathrm{~m}^{3} / \mathrm{hm}^{2}$.

In November 16, 2006, February 2007, 16 and November 7, three irrigation intensity volume is $3000 \mathrm{~m}^{3} / \mathrm{hm}^{2}$ (Figure 1). We can see that, after irrigation, soil volumetric water content in the $0 \sim 30 \mathrm{~cm}$ keep increasing and reached the maximum value. While the soil volumetric water content of $30 \sim 60 \mathrm{~cm}$ are decreasing. in $60 \sim 100 \mathrm{~cm}, 100 \sim 150 \mathrm{~cm}$ these two depth intervals ,the soil moisture are in increasing status. With the depth increase, the water content curve was in "big-small-large" trend.

In July 10, 2007, July 200723 and August 16 three irrigation intensity volume is $2250 \mathrm{~m}^{3} / \mathrm{hm}^{2}$ (Figure2). We found that, after irrigation, depth in $0 \sim 30 \mathrm{~cm}$, water content is increasing. in $30 \sim 60 \mathrm{~cm}$, they are still increasing. While slightly decreased happens in $60 \sim 100 \mathrm{~cm}$ depth. Buried deep in the $100 \sim 150 \mathrm{~cm}$. The soil volumetric moisture content increase again. As the depth increase, soil volumetric moisture content was in the "large-large-small-large" trend, the soil moisture curve shape did not change after the irrigation.

Soil moisture characters influenced by different irrigation volume are different, soil moisture in $0 \sim 30 \mathrm{~cm}$ changed a lot after the irrigation; compared with the upper layer of soil, in $100 \sim 150 \mathrm{cmdepth}$, the moisture changes little. Analysis on characteristics of soil moisture content in cotton-growing

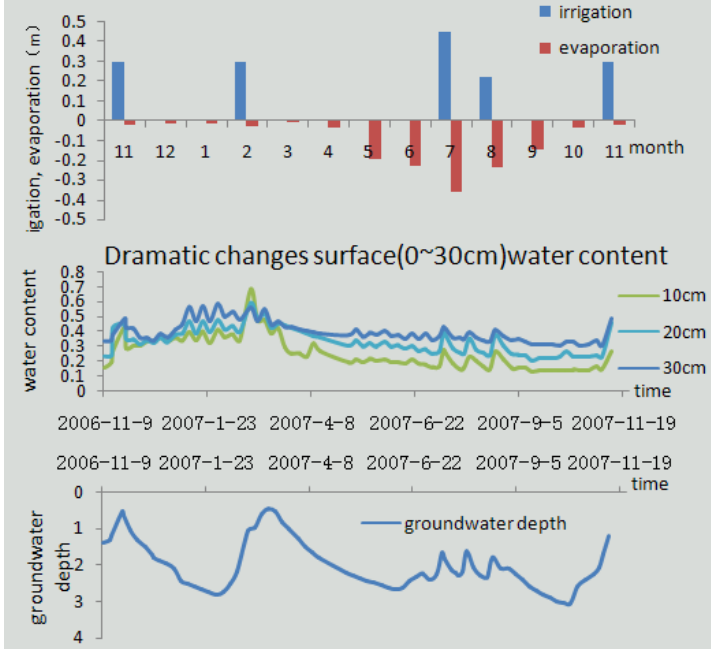

(a) conditions, the soil can be divided into four layers, they are: dramatic changes surface layer $(0 \sim 30 \mathrm{~cm})$, water supply layer $(30 \sim 50 \mathrm{~cm})$, slow-changing layer $(50 \sim 100 \mathrm{~cm})$, the stable layer $(100 \sim 150 \mathrm{~cm})$.

\subsection{Relation of Soil Water, Groundwater and Irrigation, Evaporation}

Water requirements of cotton at different growth stages are different, we will analyzing the characteristics of the four-layer moisture and groundwater irrigation and evaporation changes of relationship between soil water and groundwater.

Dramatic changes surface layer $(0 \mathrm{~cm} \sim 30 \mathrm{~cm})$ (Figure 3a), which is also known as changing layer, this layer is influenced by meteorological conditions and the texture, soil moisture content changed a lot. In November 20, 2006, February 28, 2007 and April 26,in $0 \sim 30 \mathrm{~cm}$, the soil water content has a sharply fall, because of the presence of unsaturated zone ,water depth on November 24, 2006, to March 5, 2007 just began to fall. Combining meteorological data we found that with lasting rainy days in late May, soil water content in $1 \sim 20 \mathrm{~cm}$ increase a lot.

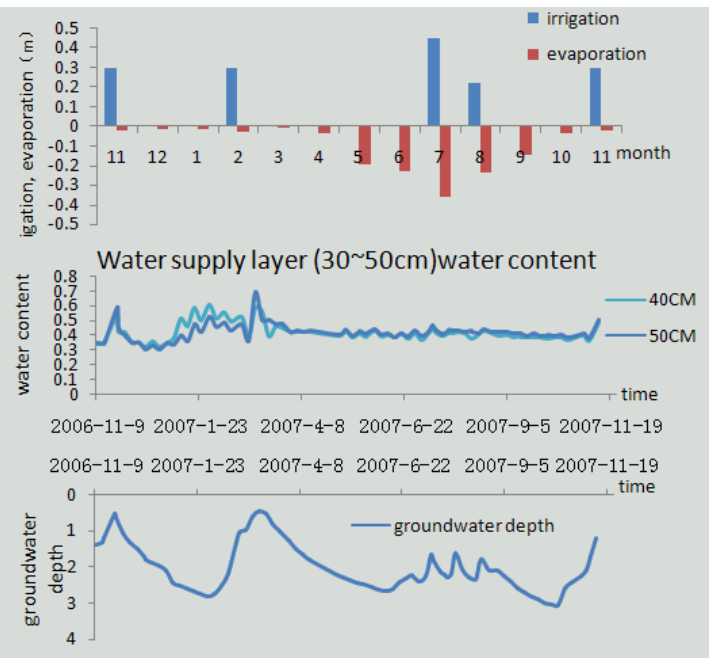

(b) 


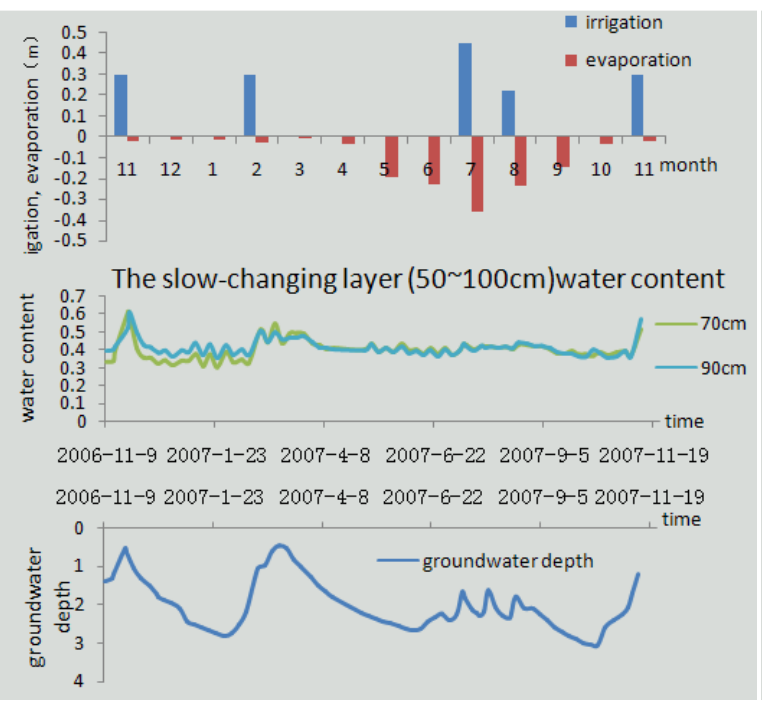

(c)

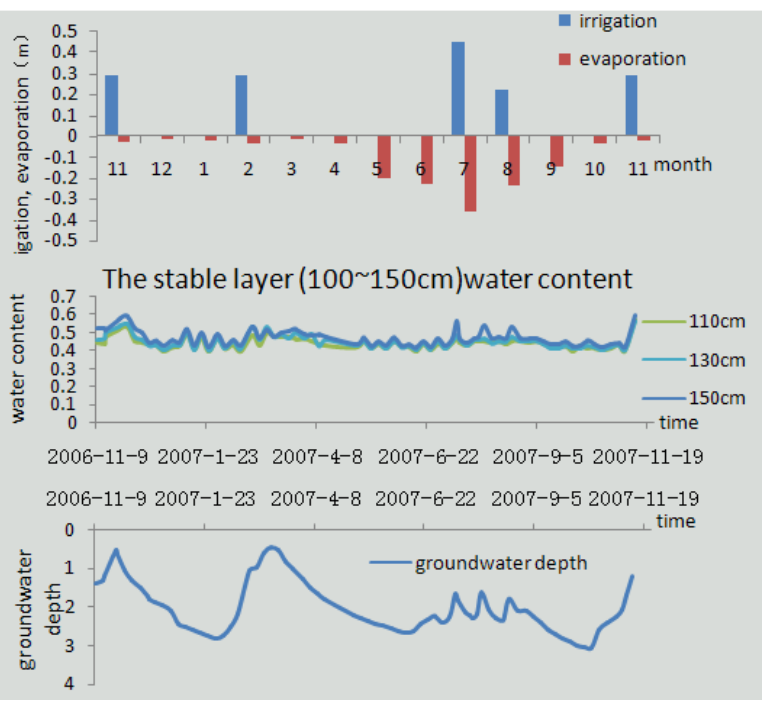

(d)

(a) in dramatic changes surface layer $(0 \sim 30 \mathrm{~cm})$; (b)in water supply layer $(30 \sim 50 \mathrm{~cm})$; (c)in slow-changing layer $(50 \sim 100 \mathrm{~cm})$; (d)in the stable layer $(100 \sim 150 \mathrm{~cm})$.

Figure 3. Relation of soil water, groundwater and irrigation, evaporation in four layers.

Water supply layer $(30 \sim 50 \mathrm{~cm})$ (Figure 3b), also known as a potential supply of water or moisture storage layer, where soil water content reaches a high value 3 days after irrigation.

Slow-changing layer $(50 \sim 100 \mathrm{~cm})(3 \mathrm{c})$, known as moisture barrier, it prevents water from flowing to the upper layers, the soil moisture content was smaller compared with other layers, from the figure we can see that, water changes is little over time, compared with the curves of the groundwater, the up-down volatility is really small, it has a stable state. To farm crops, a little water can be absorbed directly from this layer.

Stable layer (100 150cm) (figure 3d), soil moisture content is smaller, changing characteristics was the same with other layers.

From the figure we can find the relation of groundwater, irrigation and evaporation, groundwater rising means that it gets recharge from outside conditions. The upper part of the figures reflects the irrigate and evaporate conditions in comprehensive observation site. To satisfy the cotton growing needs, we take winter irrigation in November 16, 2006, that is why the depth of groundwater rise sharply between February 2007 and November 16, 2006.For spring irrigation, in early
February, the water table rose again. Soil evaporating rate begin to increase from March to September, during this period, the depth of groundwater keeps stay in a low level, due to the growing demand of cotton, the frequency of irrigation is high, which guarantees the cotton's growing in bud stage and boll-forming stage's demand.

Overall, the depth of groundwater fluctuation corresponds to the trends in evaporation and irrigation, while the change of groundwater level was a bit later than the external conditions, typically rainfall drop into the soil from the surface through the soil into groundwater, this process is known as rainfall infiltration. Ground-water flow system is spatial three-dimensional, it is one of the main differences between the groundwater and surface water.

\subsection{Analysis the Relation Between Soil Water and Groundwater}

We explore precisely by linear fitting relationship between soil water and groundwater, choose the meteorological observation data from March 5, 2007 to June 30, 2007.
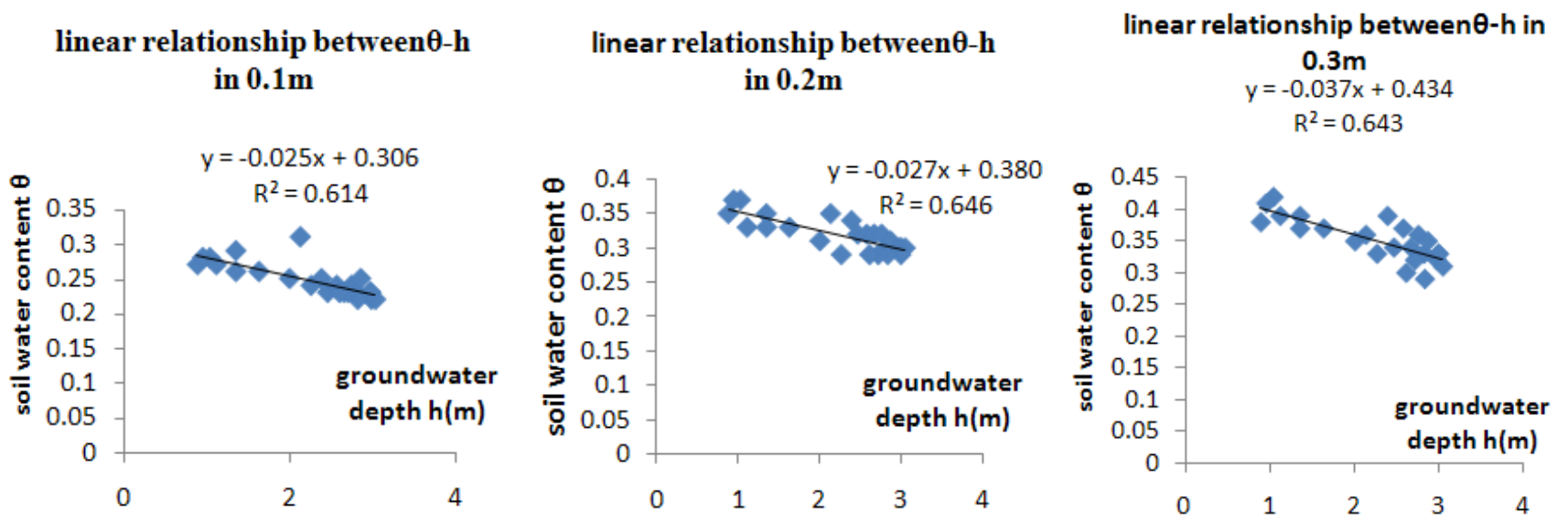


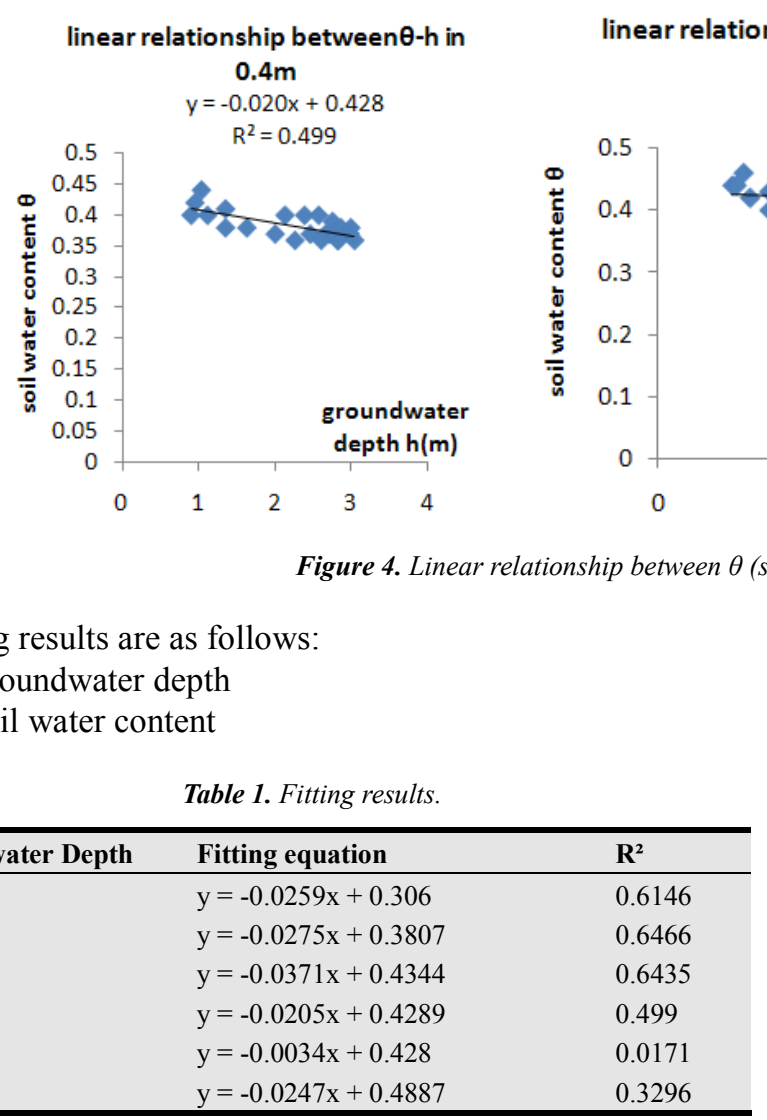

By fitting results we know that $\mathrm{x}$-groundwater and $\mathrm{y}$-soil water content has a certain relationship. By $\mathrm{R}{ }^{2}$ 's numerical value shows that, from $0.1 \mathrm{~m}$ to $0.7 \mathrm{~m}$, with the depth become larger , $\mathrm{R}^{2}$ act in a----"big-small-large" trend, we explain this by following reasons: First of all, $0-0.3 \mathrm{~m}$ belongs to the dramatic changes surface layer, meteorological fields did not have irrigation, in arid and semi-arid climate, soil water content were mainly rely on capillary action taken from the groundwater, that is to say, soil moisture and groundwater have closer relationship; Secondly, $0.4 \mathrm{~m}--0.5 \mathrm{~m}$ is in water supply layer, which has a little change in water content, also this layer belongs to the intermediate connections, so it's correlation to groundwater are not close $; 0.5 \mathrm{~m}-0.7 \mathrm{~m}$ belongs to the slowly varying layers in the hierarchy; When the surface moisture changes, underlying moisture will change after as a supplier, it has the deepest correlation between soil moisture and groundwater .This process can be described as---sucking water from a cup through a straw, surface moisture is the water sucked out by mouth, water in the middle layer represents the water in the suck, water in the deeper part in soil is the cup, the quantity of water you can sucked out depends on how much water you have in the cup, with water being sucked out, water in the cup being reduced, so in the top and bottom of the straw have closer relationship with water. While straw is the media, water in the straw never reduce, so it's relevance are low.

\section{Conclusion and Recommendations}

Through the data from November 10, 2006 to November 11, 2007 comprehensive observations of field-irrigation system, soil moisture analysis and research, combined with cotton-growing knowledge, vertical variation of soil moisture are divided into four layers: dramatic changes surface layer $(0 \sim 30 \mathrm{~cm})$, water supply $(30 \sim 50 \mathrm{~cm})$, the slowly varying $(50 \sim 100 \mathrm{~cm})$ and stable layer $(100 \sim 150 \mathrm{~cm})$.

Combining meteorological and groundwater data, it is not difficult to find, with the presence of unsaturated zone, groundwater has a lag change .Combined with four characteristic curves of soil moisture, we draw the following conclusions: (1) Water table increases soil moisture is more stable, and the smaller the correlation of soil water. (2) Soil water and groundwater relationship follows the principle of conservation of water, that is, soil water and groundwater recharge each other with the amount constant. (3) Groundwater recharge occurs mainly in evaporation in soil, soil water became groundwater primarily occurs when precipitation and irrigation happened.

Reasonable irrigation time and irrigation volume can make cotton well developed, cotton development need water in summer, extremely in July to September, during this time, cotton is in bud and boll-forming period, they need more water. Also this time in Xinjiang Aksu area, daily evaporation rate is large, the government department should take intensive irrigation during July to September. Aksu basin water resources became more and more limited in recent years, we should strengthen the development of irrigation policy.

\section{References}

[1] Dong Cheng, Wang Wenke. relationship between groundwater and vegetation in maowusu sandy land [j]. Journal of Jilin University, 2012, 42 (1), 4-5.

[2] Han Shuangping, Jing Enchun. Transformation between Soil Water and Groundwater under the condition of Planting.[J] Hydrology. 2005, 25(2): 9-14.

[3] He Junqi, ultra. spatial variation characteristics of soil moisture under different irrigation quota [j]. water-saving irrigation, 2010, 28 (5): 28-29.

[4] Lei Zhidong, Yang shixiu, Chessin. soil water Dynamics [m]. Beijing: Tsinghua University Press, 1988: 52-55. 
[5] Yu-Jun Cui. Experimental study on water evaporation from sand using environmental chamber. [J]. NRC, 2015, 51(11): $115-128$.

[6] Ning Lu [beauty], Williang J. Likos. of unsaturated soil mechanics [m]. Wei Chang Fu, Hou long, translate Jian Wenxing. Beijing: higher education press, 2012: 136-137. [3] Wei-Kang Song.

[7] Golden Court, Hou Guang, Yin Lihe. groundwater hydrology and ecology of natural vegetation in arid and semi-arid region in response to [j]. arid land geography, 2011 (9), 145-148.

[8] Scarlet-yan, Li Peicheng. variation law of soil moisture in arid region shallow groundwater zone [d] in Yangling, Northwest Sci-Tech University, 2014.

[9] The dagu River middle reaches of the relation between soil water and shallow groundwater [j] soil, 2015 (3), 547-557.

[10] The horse shoe a. soil moisture status and progress of research [j]. World Forestry Research, 1997 (5), 26-32.

[11] Wang Yanlin, Wang Zeyuan. groundwater in northern Shaanxi sand beach area of ecology-oriented programmes on sustainable development [j]. geology bulletin, 2008, 27 (8): 33-34.
[12] Wang Yiqing, Jean Bartels, Wei Xianjun, et al. study on soil moisture dynamic characteristics of [j]. Inner Mongolia forestry science and technology, 2008, 34 (4): 16-18.

[13] Cheng Jian feng. analysis on the characteristics of soil water in the aeration zone [j]. advances in water science, 2009, 31 (1): 357-363.

[14] HP. Guang Wu spring soil moisture change rule of cotton in new irrigation area [j]. Gansu meteorological, 1998, 16 (3): 25-28.

[15] Yang Zeyuan and Wang Wenke. caused by groundwater in arid and semi-arid area and its evaluation index system of supergene eco-effect [j]. arid land resources and environment, 2006, 20 (3): 229-233.

[16] Mo Zhixin, Wang Jiping. characteristic analysis of soil moisture under different vegetation in upper reaches of the Tarim River area [j]. Hubei Academy of agricultural sciences, 2008, 47 (7): 785-787.

[17] Liu Weimin, Pu Jin Chung Yao Xiaohong, et al. Tin Shui Wai growing variation of soil moisture and winter wheat yield [j]. agricultural research in the dry areas, 2008, 26 (3): 29-32. 